\title{
Maternal Depressive Symptoms During and After Pregnancy and Psychiatric Problems in Children
}

\section{Lahti, Marius}

2017-01

Lahti , M , Savolainen , K, Tuovinen , S , Pesonen , A-K, Lahti , J , Heinonen , K , Hämäläinen , E , Laivuori , H , Villa , P , Reynolds , R M , Kajantie , E \& Räikkönen , K 2017 , ' Maternal Depressive Symptoms During and After Pregnancy and Psychiatric Problems in Children ' , Journal of the American Academy of Child and Adolescent Psychiatry, vol. 56 , no. 1 , pp. 30-39 . https://doi.org/10.1016/j.jaac.2016.10.007

http://hdl.handle.net/10138/231659

https://doi.org/10.1016/j.jaac.2016.10.007

publishedVersion

Downloaded from Helda, University of Helsinki institutional repository.

This is an electronic reprint of the original article.

This reprint may differ from the original in pagination and typographic detail.

Please cite the original version. 


\title{
Maternal Depressive Symptoms During and After Pregnancy and Psychiatric Problems in Children
}

\author{
Marius Lahti, PhD, Katri Savolainen, MA, Soile Tuovinen, PhD, Anu-Katriina Pesonen, PhD, \\ Jari Lahti, PhD, Kati Heinonen, PhD, Esa Hämäläinen, PhD, Hannele Laivuori, PhD, Pia M. Villa, MD, \\ Rebecca M. Reynolds, PhD, Eero Kajantie, PhD, Katri Räikkönen, PhD
}

Objective: Maternal depressive symptoms during pregnancy are associated with increased risk of psychiatric problems in children. A more precise understanding of the timing of the symptoms during pregnancy and their independence of other prenatal and postnatal factors in predicting child psychopathology risk is needed. We examined whether maternal depressive symptoms during pregnancy predict child psychiatric problems, whether these associations are trimester- or gestational-week-specific and / or independent of pregnancy disorders, and whether maternal depressive symptoms after pregnancy mediate or add to the prenatal effects.

Method: The study sample comprised 2,296 women and their children born in Finland between 2006-2010, participating in the prospective pregnancy cohort study Prediction and Prevention of Preeclampsia and Intrauterine Growth Restriction (PREDO) and followed up from 1.9 to 5.9 years of age. The women completed the Center for Epidemiologic Studies Depression Scale biweekly between gestational weeks + days $12+0 / 13+6$ and $38+0 / 39+6$ or delivery. In the follow-up, they completed the Beck Depression Inventory-II and Child Behavior Checklist 11/2-5.
Results: Maternal depressive symptoms during pregnancy predicted significantly higher internalizing (0.28 SD unit per SD unit increase [95\% CI $=0.24-0.32])$, externalizing (0.26 [0.23-0.30]), and total problems (0.31 [0.27-0.35]) in children. These associations were nonspecific to gestational week and hence pregnancy trimester, independent of pregnancy disorders, and independent of, although partially mediated by, maternal depressive symptoms after pregnancy. Psychiatric problems were greatest in children whose mothers reported clinically significant depressive symptoms across pregnancy trimesters and during and after pregnancy.

Conclusion: Maternal depressive symptoms during pregnancy predict increased psychiatric problems in young children. Preventive interventions from early pregnancy onward may benefit offspring mental health.

Key words: antenatal, depression, childhood mental health, psychiatric symptoms, prospective study

J Am Acad Child Adolesc Psychiatry 2017;56(1):30-39.
M aternal depressive symptoms affect a large proportion of pregnancies, with $7.4 \%$ to $20 \%$ of women experiencing clinically significant levels of depressive symptoms at different stages of pregnancy. ${ }^{1,2}$ These symptoms may alter the intrauterine environment, expose the fetus to unnecessarily high levels of maternal glucocorticoids $^{3-5}$ and pro-inflammatory cytokines, ${ }^{6,7}$ and "program" an adverse offspring phenotype, thereby explaining why maternal depressive symptoms during pregnancy predict an increased risk of psychiatric problems in the offspring. ${ }^{8-19}$

Yet, it still remains unclear whether maternal depressive symptoms during pregnancy are an independent risk factor for child psychiatric problems. ${ }^{8-19}$ In the Avon Longitudinal Study of Parents and Children (ALSPAC), which is one of the two largest studies that have examined the consequences

CG Clinical guidance is available at the end of this article.

Supplemental material cited in this article is available online. of maternal depressive symptoms during pregnancy on the offspring, maternal depressive symptoms measured at gestational week 18 or 32 predicted higher risks of attention problems in the offspring in early childhood, ${ }^{17}$ and emotional and behavioral problems in pre-puberty. ${ }^{12}$ In the Generation R study, the other of the two largest studies, maternal depressive symptoms at gestational week 20 were associated with higher risk of offspring attention problems ${ }^{17}$ and internalizing and externalizing problems ${ }^{18}$ in early childhood. In ALSPAC, the associations remained significant after adjusting for maternal depressive symptoms at the time of rating the child's psychiatric problems. ${ }^{12,17}$ However, in Generation $R$, the associations were no longer significant, ${ }^{17,18}$ challenging the assumption that the effects of maternal depression would be due to an adverse intrauterine environment.

Although differences in sample characteristics and assessment tools may at least partially explain the contradictory findings, these and some other previous, smallerscale studies were limited to assessing maternal depressive symptoms "during the past 7 days or last 2 weeks" only once or twice during pregnancy. ${ }^{8-19}$ Hence, it remains 
unknown whether some developmental periods during pregnancy are more vulnerable than others to the effects of maternal depressive symptoms, and whether feeling depressed throughout pregnancy is more harmful for the offspring than feeling depressed only for 1 or 2 weeks at one or two arbitrary timepoints. However, since depressive symptoms show high stability, 8,12 disentangling gestationweek-specific or trimester-specific effects of maternal depressive symptoms during pregnancy may prove difficult. It also remains unclear whether maternal depressive symptoms concurrent to rating the child's problems add to, rather than account for, or mediate the effects of prenatal environmental adversities.

Accordingly, we examined whether depressive symptoms measured biweekly from gestational week 12 onward up to 14 times during pregnancy in a large cohort of pregnant Finnish women predict the levels of psychiatric problems in their 1.9- to 5.9-year-old children, and whether maternal depressive symptoms at the time of rating the child's problems add to, account for, or mediate any effects of maternal depressive symptoms during pregnancy. Another novel contribution of this study was to account for possible confounding by common pregnancy disorders: pre-pregnancy obesity, gestational diabetes, and hypertension-spectrum pregnancy disorders. According to previous studies, these disorders co-occur with depressive symptoms ${ }^{20,21}$ and are associated with offspring psychiatric problems. ${ }^{22-24}$

\section{METHOD}

\section{Participants}

The Prediction and Prevention of Preeclampsia and Intrauterine Growth Restriction (PREDO) study enrolled 4,785 pregnant women, of whom 4,777 (because of 8 miscarriages or stillbirths) gave birth to a singleton live-born child between 2006 and 2010. ${ }^{4,5,25}$ The women were recruited to the study when they visited antenatal clinics at one of the 10 study hospitals in Southern and Eastern Finland for their first ultrasound screening between $12+0$ and $13+6$ weeks+days of gestation. Of these women, $3,402(71.2 \%$ of those with live-born offspring) filled in the biweekly depressive symptoms questionnaire during pregnancy.

In 2011 to 2012, a total of 4,586 women and their children from the original sample were invited for a follow-up (three children had died after birth and before the follow-up, 33 did not have data in the Finnish nation-wide medical birth register, 55 women had declined participation in a follow-up, and for 100 women, addresses were not traceable). Of these, 2,667 women and children $(58.2 \%$ of those invited) participated.

Of the 4,586 mothers invited to the follow-up, 3,279 had data on depressive symptoms during pregnancy, and 2,296 had both pregnancy and follow-up data available. The current study sample comprises these 2,296 women and their 1.9- to 5.9-year-old children (1,161 boys, 1,135 girls; $70.0 \%$ of those with data on depressive symptoms during pregnancy and invited to the follow-up).

In comparison to the nonparticipants in the original sample ( $\mathrm{n}=2,489)$, the current study participants were older at delivery (mean difference $=0.7$ years, $p<.001$ ), had more often tertiary education $(62.8 \%$ vs. $54.7 \%, p<.001)$, were less often obese (body mass index $\left.[\mathrm{BMI}] \geq 30 \mathrm{~kg} / \mathrm{m}^{2}\right)$ before pregnancy $(12.3 \%$ vs. $15.9 \%$, $p<.001)$, and less often multiparous $(58.1 \%$ vs. $64.4 \%, p<.001)$, smoked less often throughout pregnancy $(2.8 \%$ vs. $7.1 \%, p<.001)$, and more often had a daughter $(49.4 \%$ vs. $46.2 \%, p=.03)$. All participating mothers signed informed consent forms. The PREDO study protocol was approved by ethical committees of the Helsinki and Uusimaa Hospital District.

\section{Maternal Depressive Symptoms}

The women completed the Center for Epidemiologic Studies Depression Scale (CES-D) ${ }^{26}$ biweekly up to 14 times throughout pregnancy starting from $12+0 / 13+6$ gestation weeks+days until $38+0 / 39+6$ gestation weeks+days or delivery. The 20 CES-D questions were rated on a scale from none of the time (0) to all of the time (3). Higher scores indicate more depressive symptoms during the past week, and a sum-score of $\geq 16$ indicated risk for clinical depression. ${ }^{26,27}$

In the follow-up, the women completed the Beck Depression Inventory-II (BDI-II), which comprises 21 items, each containing four statements (scored from 0 to 3 ) reflecting increasing severity of depressive symptoms during the past 2 weeks. ${ }^{28}$ A sum-score of $\geq 14$ indicates at least mild depressive symptomatology. ${ }^{28,29}$

Both depression scales have good psychometric properties, ${ }^{26,31}$ and the CES-D has been used extensively and validated also in pregnant populations. ${ }^{30,31}$ In our sample, the CES-D (Cronbach's $\alpha=.88-.92$ in the 14 biweekly measurement points) and the BDI-II $(\alpha=.91)$ showed high internal consistency.

\section{Child Psychiatric Problems}

Child Behavior Checklist for ages $1 \frac{1 / 2}{2}$ to 5 years (CBCL/11/2-5), filled in by the child's mother, comprises 99 problem items rated on a scale of not true (0) to very true or often true (2). ${ }^{32}$ The CBCL/11/2-5 has good test-retest reliability, internal consistency, and criterion validity. ${ }^{32,33}$ The CBCL/1 $1 \frac{1}{2}-5$ yields scores for three main scales (internalizing, externalizing, and total problems), seven syndrome scales (emotionally reactive, anxious/depressed, somatic complaints, withdrawn, sleep problems, attention problems, and aggressive behavior), and five DSM-oriented scales (affective, anxiety, pervasive developmental, attention-deficit/hyperactivity, and oppositional defiant problems). ${ }^{34} \mathrm{~A} t$ score of $\geq 60$ on the main and of $\geq 65$ on the syndrome and DSM-oriented scales indicates at least borderline clinically significant problems. ${ }^{32}$

\section{Pregnancy Disorders}

Data on maternal pregnancy disorders were extracted from medical reports independently verified by a clinical jury and/or from the Finnish Medical Birth Register. ${ }^{25}$ These included pre-pregnancy obesity (BMI $\geq 30 \mathrm{~kg} / \mathrm{m}^{2}$ vs. BMI $<30 \mathrm{~kg} / \mathrm{m}^{2}$ ), hypertension spectrum pregnancy disorders (preeclampsia, gestational hypertension; yes/no), and gestational diabetes (yes/no)..$^{21,25,34,35}$

\section{Covariates}

These included maternal age at delivery (years), smoking during pregnancy (did not smoke/quit during first trimester/smoked throughout pregnancy), parity (primiparous/multiparous), chronic hypertension (yes/no), type 1 diabetes (yes/no), child's sex, gestational length (weeks), birthweight (grams), and family structure at childbirth (cohabitation/marriage vs. single parent), with data extracted from medical reports and/or Medical Birth Register; maternal history of physician-diagnosed depression before pregnancy (yes/no), psychotropic medication use during pregnancy (antidepressants, other [barbiturates, sedatives, antipsychotics] vs. no), alcohol use during pregnancy (yes/no), and education level (basic/secondary vs. tertiary), each self-reported in a questionnaire given to the mothers at $12+0$ to $13+6$ weeks+days of gestation; and 
child's age at follow-up (years), which was reported in conjunction with filling in the CBCL questionnaire.

\section{Data Analysis}

We examined the course of depressive symptoms during pregnancy with latent profile analysis and Pearson correlation analysis.

Next, we inspected the crude unadjusted mean differences of maternal depressive symptoms across the 14 measurement points during pregnancy according to child internalizing, externalizing, and total problems scores above and below the borderline clinical cutoff, and calculated Cohen's $d$ values for effect sizes.

We then used linear regression analyses to test associations between maternal depressive symptoms during pregnancy and child internalizing, externalizing, and total problems. We examined gestation week-specific effects and also calculated a trimesterweighted mean value of depressive symptoms across pregnancy (mean of the only value from first pregnancy trimester and the mean values of second trimester and third trimester) and square-root transformed the values to normalize the distributions. Because scores in the CBCL/1 $1 \frac{1}{2}-5$ syndrome and DSM-oriented scales below 50 were truncated into 50 according to the manual, ${ }^{32}$ resulting in strongly skewed distributions and a "floor effect," Tobit regressions were used in the analyses of these scales. To facilitate interpretation, both the predictor and outcome variables were standardized to the mean of 0 and SD of 1 .

The associations of maternal depressive symptoms during pregnancy with child psychiatric problems were examined in four different linear or Tobit regression models. Model 1 was adjusted for child's age and sex. Model 2 was adjusted for the covariates in model 1 and family structure, maternal age at childbirth, parity, education level, type 1 diabetes, chronic hypertension, history of depression before pregnancy, antidepressant and other psychotrophic medication use, alcohol use and smoking during pregnancy, gestation length, and infant's birthweight adjusted for sex and gestation length. Model 3 was adjusted for the model 2 covariates and prepregnancy obesity, gestational diabetes, and hypertensionspectrum pregnancy disorders. Model 4 was adjusted for the model 3 covariates and maternal depressive symptoms after pregnancy at the time of rating the child's psychiatric problems.

With linear and/or Tobit regressions, we also tested whether child psychiatric problem scores increased according to the number of pregnancy trimesters $(0,1,2,3)$ during which the mean maternal CES-D score was above the clinical cut-off of $\geq 16$; whether child psychiatric problem scores differed among the groups of mothers identified by a latent profile analysis based on their depressive symptoms scores across pregnancy; whether maternal pregnancy disorders accounted for the effects of maternal depressive symptoms during pregnancy (analyses were adjusted for the pregnancy disorders and re-run separately in mothers with and without pregnancy disorders); and whether maternal depressive symptoms after pregnancy accounted for (postpartum depressive symptoms were added as a covariate into the fourth regression models), mediated (mediation analyses were performed with the bootstrapping method using 5000 bootstrapping re-samples with bias-corrected confidence intervals), or added to the effects of maternal depressive symptoms during pregnancy (interaction term of depressive symptoms during pregnancy $\times$ after pregnancy was entered into the regression equation followed by the main effects).

In additional analyses, we studied age-specific associations by re-running the analyses separately among children who were 1.9 to 3.9 years and 4.0 to 5.9 years of age at follow-up. We also re-ran the analyses separately among children born to mothers with and without depression diagnoses before pregnancy. Finally, in a subsample from whom we had paternal CES-D depressive symptoms data available when the children were 6 months old $(n=1,237)$, we examined whether paternal depressive symptoms confounded any effects of maternal depressive symptoms.

\section{RESULTS}

Table 1 shows the characteristics of the study sample. The CES-D scores were highly intercorrelated across pregnancy (Pearson $r$ values $0.44-0.80, p$ values <.001). Latent profile analysis identified a solution with three groups as the optimal (in comparison to solutions with fewer and larger number of groups) to depict depressive symptoms throughout pregnancy (Akaike Information Criterion $=184565.50$, sample-size-adjusted Bayesian Information Criterion $=184714.10$, Vuong-Lo-Mendell-Rubin LRT and Lo-Mendell-Rubin-adjusted likelihood ratio test $p$ values $=.02$ ). In all three groups, which differed from each other in their level of depressive symptoms, depressive symptoms showed high stability. One trajectory was described by consistently high, one by consistently moderate, and one by consistently low depressive symptom scores (Figure S1, available online). The CES-D mean score during pregnancy also correlated significantly with the BDI-II score in the follow-up $(r=.45, p<.001)$, and child internalizing, externalizing, and total problems were highly intercorrelated $(r=0.62-0.90, p<.001)$. Maternal pregnancy disorders were not associated with child psychiatric problems, but maternal history of depression before pregnancy was associated with significantly higher child internalizing, externalizing, and total psychiatric problems. Table S1 (available online) shows these and the associations of the other covariates with child psychiatric problems.

\section{Maternal Depressive Symptoms During Pregnancy and Child Psychiatric Problems}

Figure 1 (panel A) shows that at each biweekly measurement point during pregnancy, mothers whose children scored above the borderline clinical cutoffs in internalizing, externalizing, and total problems had significantly higher depressive symptom scores than mothers whose children scored below the cutoffs; these group differences were of medium effect size (Cohen's $d=0.36-0.52$ ).

Figure 1 (panel B) and Tables S2 and S3 (available online) show that the effects of maternal depressive symptoms across pregnancy and at each biweekly assessment on child internalizing, externalizing, and total problems were significant when adjusted for covariates in linear regression models 1 and 2. Table S2 (available online) shows that higher maternal mean depressive symptoms during pregnancy also predicted significantly higher CBCL syndrome-oriented and DSM-oriented problem scores of the child across Tobit regression models 1 and 2 .

As shown in Figure 2 (panel A), child internalizing, externalizing, and total psychiatric problem scores increased linearly according to the number of pregnancy trimesters during which the mother reported mean depressive symptoms above the clinical cutoff of $\geq 16$. We also compared the psychiatric problems of children of mothers with consistently high, moderate, and low depressive 
TABLE 1 Characteristics of the Sample

\begin{tabular}{|c|c|c|}
\hline Characteristic & Data Available (n) & Mean (SD)/n(\%) \\
\hline \multicolumn{3}{|l|}{ Maternal characteristics } \\
\hline Age at delivery $(y)$ & 2,296 & $31.9(4.6)$ \\
\hline Education, tertiary & 2,296 & $1,443(62.8 \%)$ \\
\hline Parity, primiparous & 2,291 & $961(41.9 \%)$ \\
\hline Family structure, single & 2,193 & $35(1.6 \%)$ \\
\hline Pre-pregnancy BMI $\left(\mathrm{kg} / \mathrm{m}^{2}\right)$ & 2,296 & $24.3(4.8)$ \\
\hline Obese $(B M I \geq 30)$ & & $283(12.3 \%)$ \\
\hline History of depression before pregnancy, Yes & 2,186 & $214(9.8 \%)$ \\
\hline Antidepressants medication use during pregnancy, Yes & 1,952 & $49(2.5 \%)$ \\
\hline Other psychotropic medication use during pregnancy, Yes & 1,952 & $14(0.7 \%)$ \\
\hline Gestational hypertension-spectrum disorder, Yes & 2,296 & $179(7.8 \%)$ \\
\hline Chronic hypertension, Yes & 2,296 & $83(3.6 \%)$ \\
\hline Gestational diabetes, Yes & 2,296 & $235(10.2 \%)$ \\
\hline Type 1 diabetes, Yes & 2,296 & $11(0.5 \%)$ \\
\hline Alcohol use during pregnancy, Yes & 2,275 & $374(16.4 \%)$ \\
\hline Smoking during pregnancy, No & 2,296 & $2,156(93.9 \%)$ \\
\hline Quit during the first trimester & & $75(3.3 \%)$ \\
\hline Smoked throughout pregnancy & & $65(2.8 \%)$ \\
\hline \multicolumn{3}{|l|}{ Depressive symptoms during pregnancy } \\
\hline $\begin{array}{l}\text { Trimester-weighted mean of center for epidemiologic studies depression scale } \\
\text { sum-scores }\end{array}$ & 2,296 & $11.4(6.4)$ \\
\hline $\begin{array}{l}\text { Trimester-weighted mean of center for epidemiologic studies depression scale } \\
\text { sum-scores } \geq 16\end{array}$ & 2,296 & $489(21.3 \%)$ \\
\hline \multicolumn{3}{|l|}{ Depressive symptoms after pregnancy } \\
\hline BDI-II sum-score & 2,269 & $6.4(6.3)$ \\
\hline BDI-Il sum-score $\geq 14$, Yes & 2,269 & $274(12.1 \%)$ \\
\hline \multicolumn{3}{|l|}{ Child characteristics } \\
\hline Sex, male & 2,296 & $1,161(50.6 \%)$ \\
\hline Gestational age (wk) & 2,296 & $39.9(1.6)$ \\
\hline Birthweight (g) & 2,296 & $3,520.9$ (510.9) \\
\hline Age at follow-up (y) & 2,296 & $3.5(0.7)$ \\
\hline \multicolumn{3}{|l|}{ Child Behavior Checklist/1 1⁄2-5 Psychiatric Problems } \\
\hline \multicolumn{3}{|l|}{ Main scales } \\
\hline Internalizing problems & 2,296 & $45.8(9.4)$ \\
\hline Scored above the borderline clinical cutoff, Yes & 2,296 & $197(8.6 \%)$ \\
\hline Externalizing problems & 2,296 & $47.5(9.1)$ \\
\hline Scored above the borderline clinical cutoff, Yes & 2,296 & $225(9.8 \%)$ \\
\hline Total problems & 2,296 & $46.4(9.2)$ \\
\hline Scored above the borderline clinical cutoff, Yes & 2,296 & $183(8.0 \%)$ \\
\hline \multicolumn{3}{|l|}{ Syndrome scales } \\
\hline Emotionally reactive & 2,296 & $52.9(4.8)$ \\
\hline Anxious/depressed & 2,296 & $51.1(2.9)$ \\
\hline Somatic complaints & 2,296 & $54.0(5.9)$ \\
\hline Withdrawn & 2,296 & $53.0(4.5)$ \\
\hline Sleep problems & 2,296 & $54.1(5.5)$ \\
\hline Attention problems & 2,296 & $51.9(3.5)$ \\
\hline Aggressive behavior & 2,296 & $53.1(5.2)$ \\
\hline \multicolumn{3}{|l|}{ DSM-oriented scales } \\
\hline Affective problems & 2,296 & $53.6(5.0)$ \\
\hline Anxiety problems & 2,296 & $52.1(4.2)$ \\
\hline Pervasive developmental problems & 2,296 & $53.3(5.3)$ \\
\hline ADHD problems & 2,296 & $52.1(3.8)$ \\
\hline ODD problems & 2,296 & $53.7(5.5)$ \\
\hline
\end{tabular}


FIGURE 1 Maternal depressive symptoms during pregnancy and psychiatric problems in children. Note: (Panel A) Crude unadjusted means and $95 \% \mathrm{Cl}$ (error bars) of maternal biweekly depressive symptoms during pregnancy according to child's Internalizing, Externalizing, and Total Problems scores above (solid lines) and below (dashed lines) the borderline clinical cutoffs. (Panel B) Unstandardized regression coefficients (B) and $95 \% \mathrm{Cl}$ of linear regression analyses on the associations between trimesterweighted mean of maternal depressive symptoms during pregnancy and child internalizing, externalizing, and total problems in linear regression models 1 to 4 . SD = standard deviation.

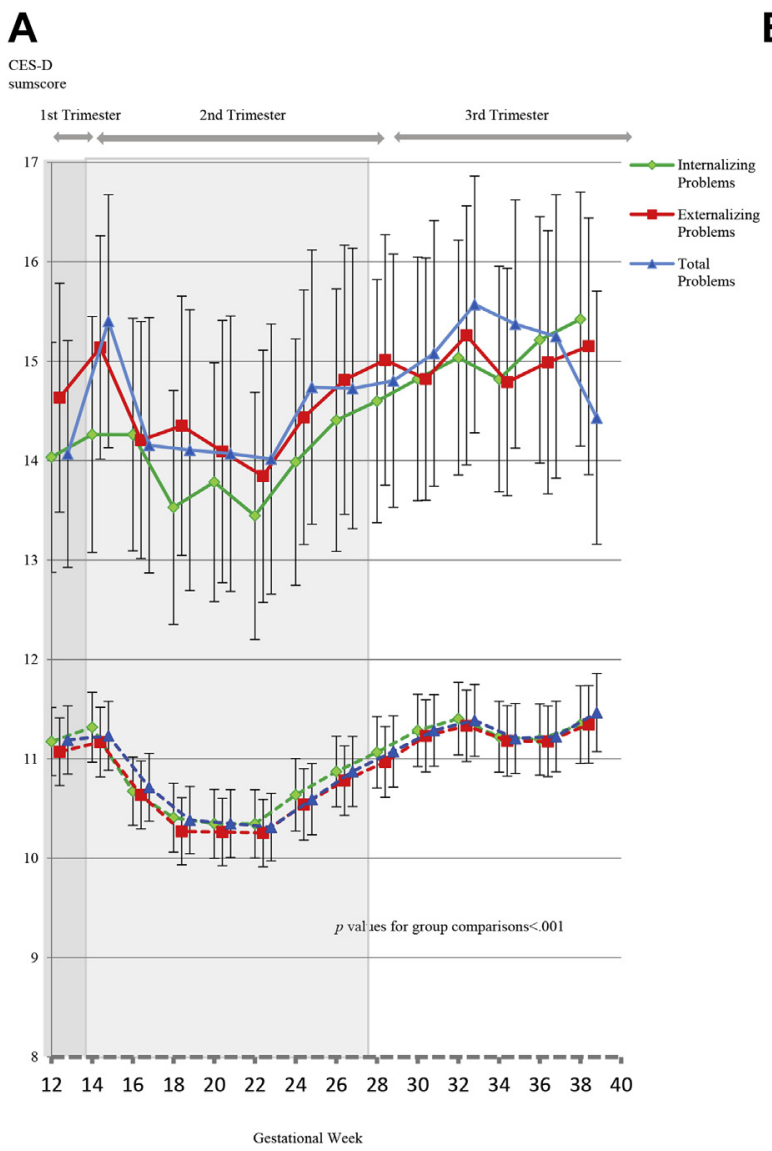

symptoms during pregnancy, as identified by the latent profile analysis. Figure 2 (panel B) shows that child internalizing, externalizing, and total psychiatric problem scores were the highest in children born to mothers who had consistently high depressive symptoms during pregnancy. Adjustments for covariates in models 1 to 4 had no effects on these associations (Figure 2).

Pregnancy Disorders, Maternal Depressive Symptoms During Pregnancy, and Child Psychiatric Problems

When we made further adjustments for maternal prepregnancy obesity, hypertension-spectrum pregnancy disorders, and gestational diabetes, all of the associations between maternal depressive symptoms during pregnancy and child psychiatric problems remained significant (Figures 1 [panel B, model 3] and 2 and Tables S2 and S3 [model 3], available online). We re-ran the analyses in groups who were and were not exposed to maternal pregnancy disorders, and in both groups, the associations were significant (Figure S2, available online).

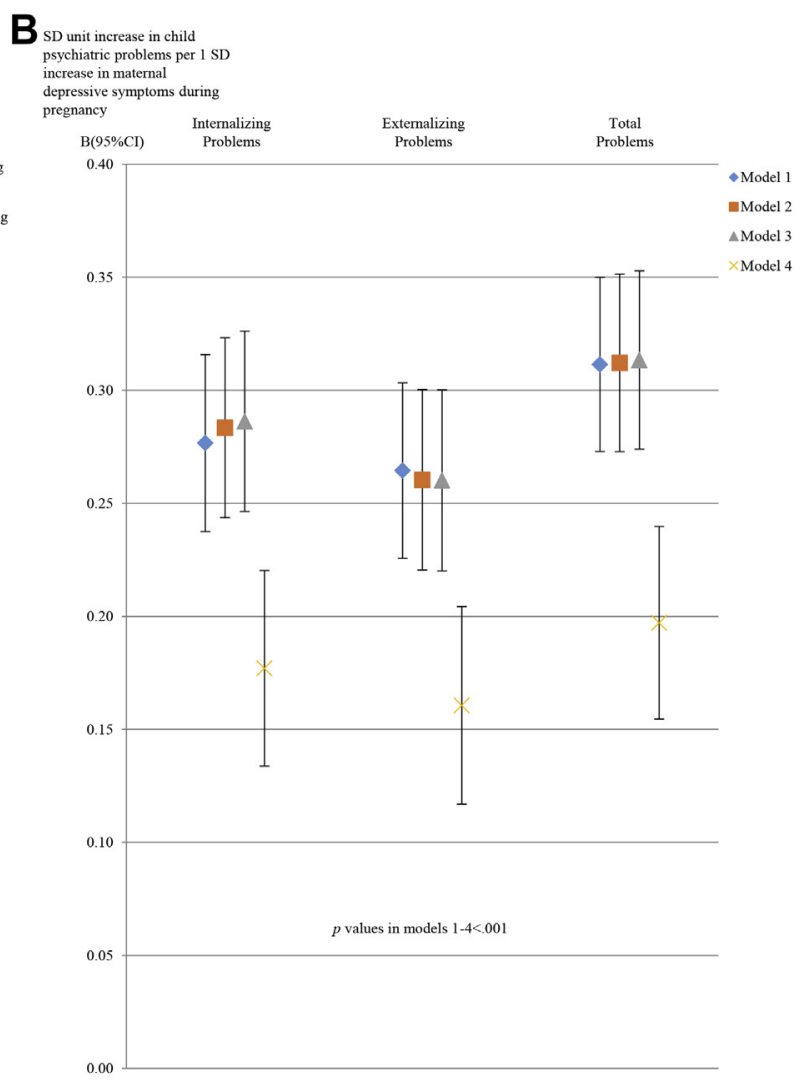

Moderating and Partially Mediating Effects of Maternal Depressive Symptoms After Pregnancy

Figures 1 (panel B, model 4) and 2 and Tables S2 and S3 (model 4, available online) show that although maternal depressive symptoms after pregnancy, concurrently to rating the child psychiatric problems, were significantly associated with higher internalizing, externalizing, and total problems as well as syndrome scale-oriented and DSM-oriented problems of the child (unstandardized regression coefficients in fourth regression models $=0.22-0.47, p$ values $<.001$ ), maternal depressive symptoms across pregnancy and at each biweekly assessment remained significant predictors of all types of child psychiatric problems after adjustment for maternal depressive symptoms after pregnancy, although in effect size these associations were somewhat attenuated. Mediation analyses demonstrated that although maternal depressive symptoms during pregnancy had a direct effect on child internalizing, externalizing, and total problems, maternal depressive symptoms after pregnancy partially mediated the prenatal effects (Figure 3). 
FIGURE 2 Additive effects of maternal trimester-specific depressive symptoms during pregnancy on child psychiatric problems. Note: (Panel A) Estimated marginal means and $95 \% \mathrm{Cls}$ of child internalizing, externalizing, and total problems according to the number of pregnancy trimesters during which the mother had mean depressive symptoms above the clinical cutoff of $\geq 16$ are shown. Estimated marginal means are adjusted for child's age and sex; $p$ values refer to linear trends in regression models 1 to 4 . (Panel B) Estimated marginal means and $95 \% \mathrm{Cl}$ of child internalizing, externalizing, and total problems in three groups identified by latent profile analysis on maternal depressive symptoms across pregnancy. Estimated marginal means are adjusted for child's age and sex; $p$ values refer to linear trends in regression models 1 to 4 .

A

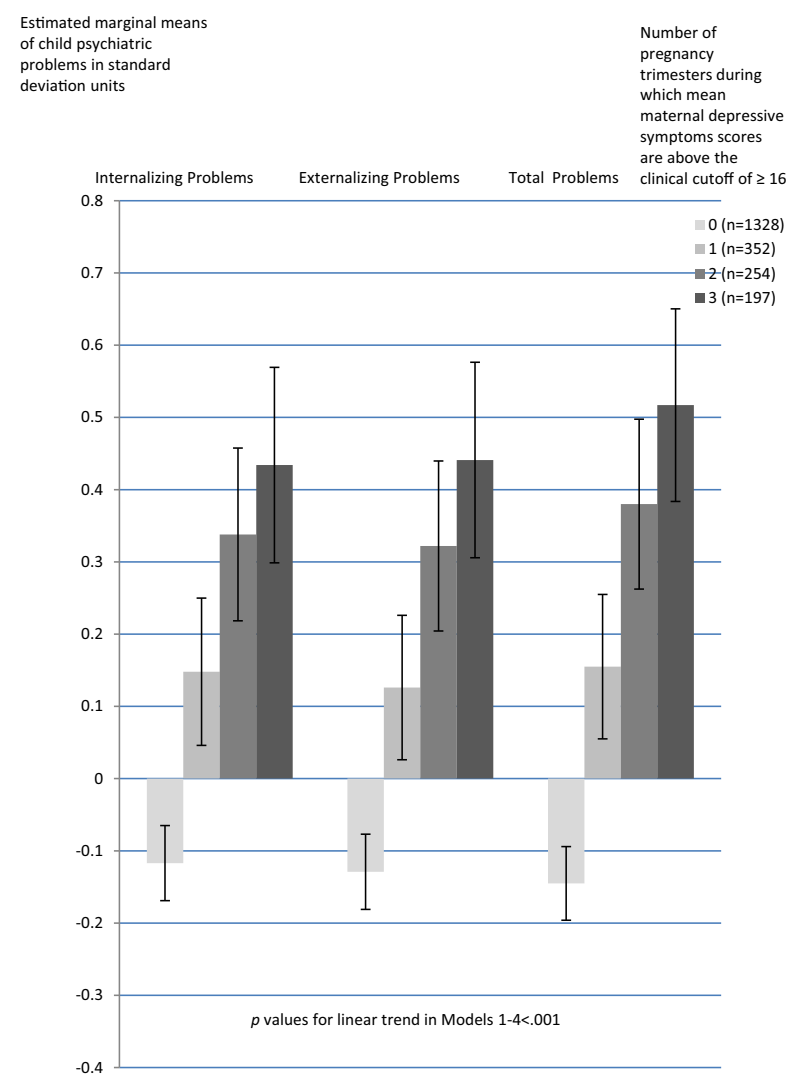

B

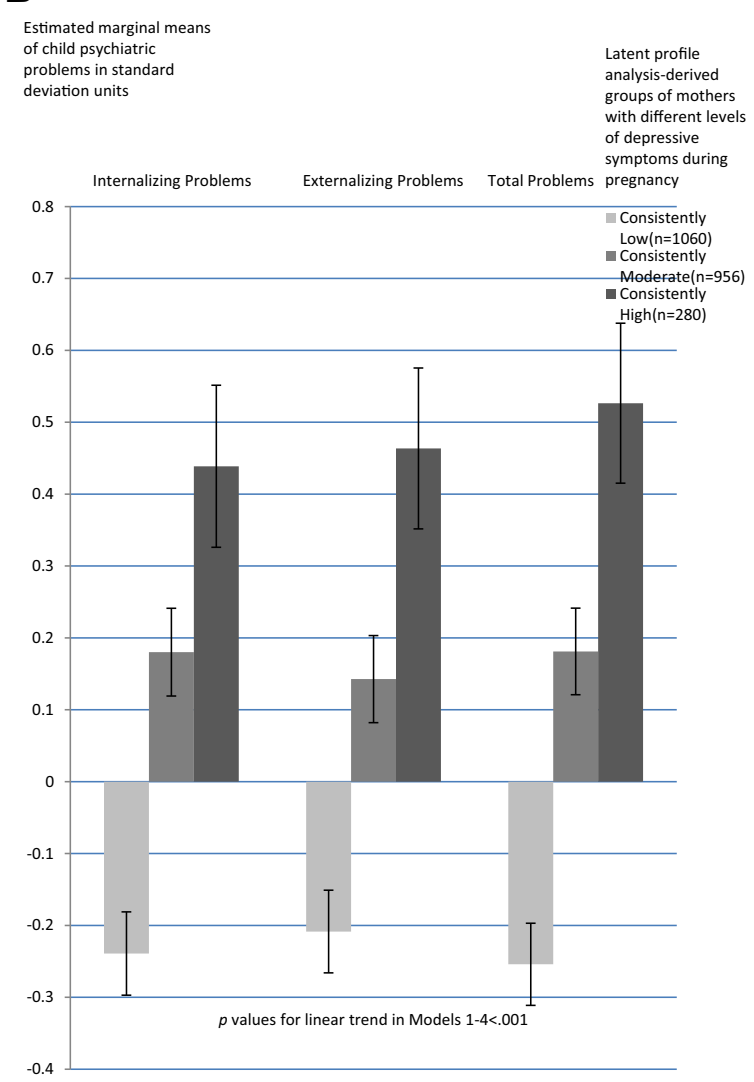

and total problems both among children who were 1.9 to 3.9 and 4.0 to 5.9 years of age.

Higher maternal depressive symptoms during pregnancy predicted higher psychiatric problems among children born to mothers both with and without a diagnosis of depression before pregnancy (Figure S3, available online). However, the associations with internalizing problems were inconsistent across models 1 to 4 among children whose mothers had been diagnosed with depression before pregnancy.

Lack of Confounding by Paternal Depressive Symptoms in Child's Infancy

At child age 6 months, 1,237 fathers assessed their depressive symptoms (mean $=7.4, \mathrm{SD}=6.0: r=0.15$, and $r=0.11$ with maternal depressive symptoms during and after pregnancy, respectively, $p$ values <.001). Linear regression analyses in this subsample showed that maternal depressive symptoms during pregnancy predicted significantly higher child internalizing, externalizing, and total problems 
FIGURE 3 Maternal depressive symptoms during pregnancy partially act via symptoms after pregnancy on child psychiatric problems. Note: Mediation analyses showing that maternal depressive symptoms during pregnancy act partially via maternal depressive symptoms after pregnancy to affect child internalizing (panel A), externalizing (panel B), and total (panel C) problems are shown. Numbers represent unstandardized regression coefficients (B), $95 \% \mathrm{Cls}$, and $p$ values. The estimates are adjusted for child's age and sex; $p$ values refer to effects in regression models 1 to 3 .
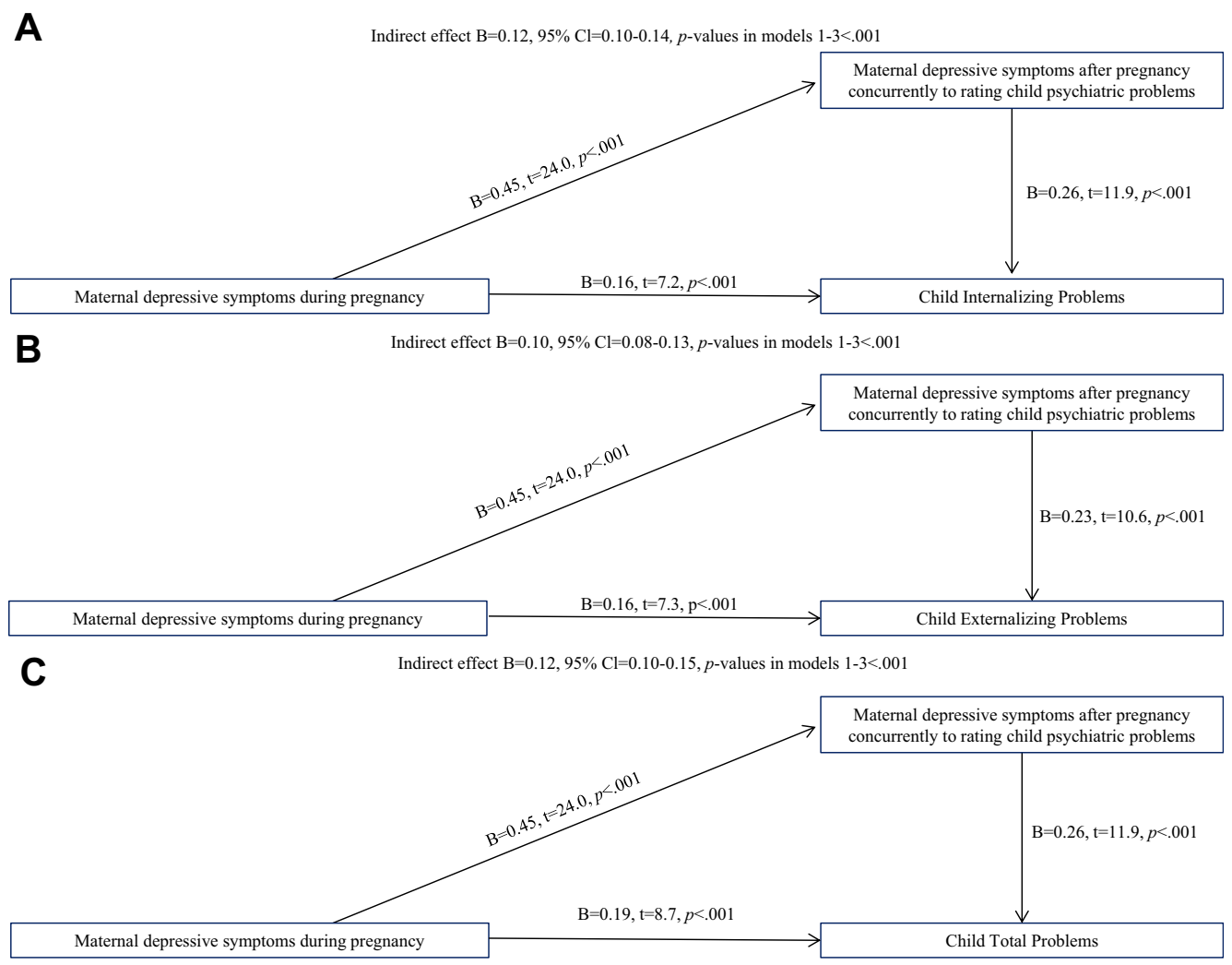

independently of model 4 covariates and paternal depressive symptoms (unstandardized regression coefficients $=0.18$, 0.15 , and 0.19 , respectively; $p$ values $<.001$ ).

\section{DISCUSSION}

Our prospective study shows that higher maternal depressive symptoms during pregnancy predicted significantly higher levels of child psychiatric problems in early childhood across all of the domains captured by the CBCL. ${ }^{32}$ Although maternal depressive symptoms after pregnancy at the time of evaluating the child's psychiatric problems were also associated with significantly higher child psychiatric problems, the prenatal effects were not accounted for by the after-pregnancy effects. Instead, higher maternal depressive symptoms after pregnancy only partially mediated the prenatal effects. Additional analyses showed that they also added to child psychiatric problems, such that children of mothers with clinically significant depressive symptoms both during and after pregnancy had the highest internalizing and total problems scores. All of the associations were independent of a number of important covariates, including common pregnancy disorders and paternal depressive symptoms when the children were 6 months old.
That the effects of maternal depressive symptoms during pregnancy on child psychiatric problems were independent of depressive symptoms after pregnancy correspond well with findings from ALSPAC ${ }^{12,17}$ but contradict findings from Generation $\mathrm{R}^{17,18}$ studies of sample size comparable to ours. In ethnic background, our sample is more similar to the ALSPAC, which comprises offspring almost entirely of white ethnicity, than it is to the multiethnic Generation $\mathrm{R}$. This offers one possible explanation why our findings differ from the findings in Generation R. Most importantly, however, our study captured depressive symptomatology throughout the entire pregnancy unprecedented by these two and any other previous studies. ${ }^{8-19}$ The multiple, repeated, biweekly measurements in our study indeed reduced measurement error and increased the reliability and internal validity of our findings. Hence, our study offers the most comprehensive view reported so far on the effects of maternal depressive symptoms during pregnancy on child psychiatric problems.

The repeated measurements allowed us also to capture any gestational-week-specific effects. This is relevant because maternal physiology changes during pregnancy and pregnant women become physiologically more stress resistant as pregnancy advances. ${ }^{36}$ Yet, we found that maternal depressive symptoms showed high stability 
FIGURE 4 Additive effects of maternal depressive symptoms during and after pregnancy on child internalizing and total problems. Note: Estimated marginal means and $95 \% \mathrm{Cls}$ of child internalizing (panel A) and total (panel B) problems according to mean maternal depressive symptoms during pregnancy above and below the clinical cutoff of $\geq 16$ on the Center for Epidemiologic Studies Depression Scale (CES-D) and after pregnancy above and below the clinical cutoff of $\geq 14$ on the Beck Depression Inventory-II (BDI-II) are shown. The estimated marginal means are adjusted for child's age and sex: $p$ values refer to linear trends in regression models 1 to 3 .

\section{A}

\section{Child internalizing}

problems in standard

deviation units

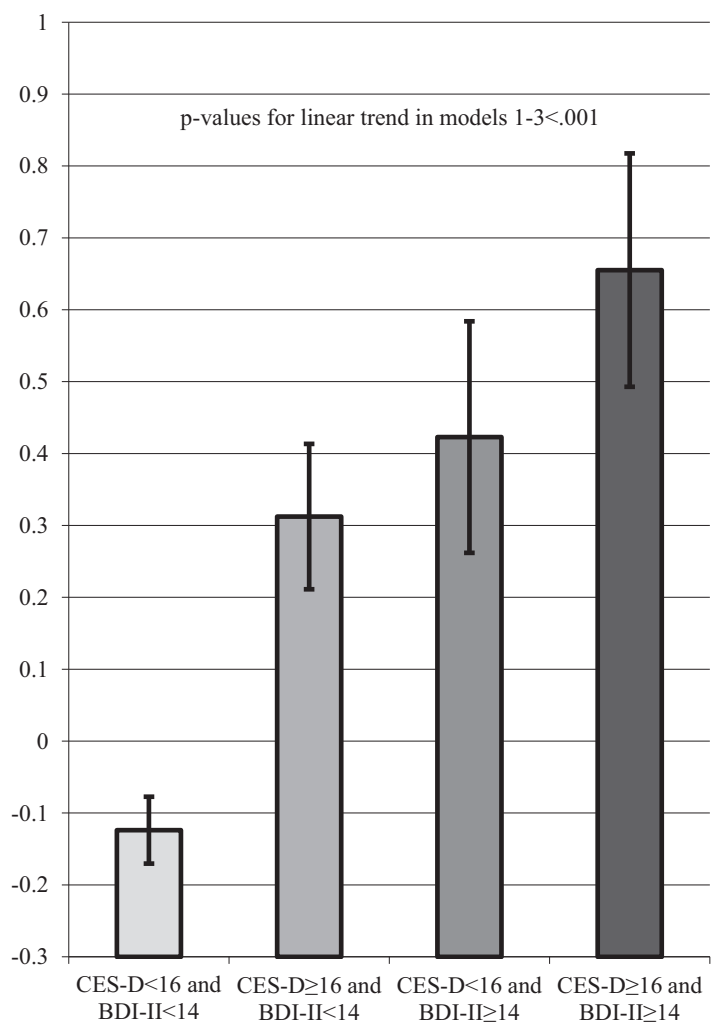

across the biweekly measurements. Therefore, it was not surprising to discover that the effects of depressive symptoms on child psychiatric problems were nonspecific to gestation week and hence pregnancy trimester. Regardless of detecting these nonspecific effects, the level of child psychiatric problems increased according to the number of pregnancy trimesters during which the mother reported clinically significant depressive symptoms. This highlights the importance of evaluating depressive symptoms multiple times during pregnancy. An alternative explanation for these findings is that they reflect both the chronicity and the severity of depressive symptoms throughout pregnancy. Although our study does not provide the means to disentangle chronicity from severity, the results of our latent profile analysis showing that child psychiatric problems were the highest in the group of mothers who had consistently high depressive symptoms during pregnancy favor this interpretation.

\section{B}

Child total problems
in standard deviation
units

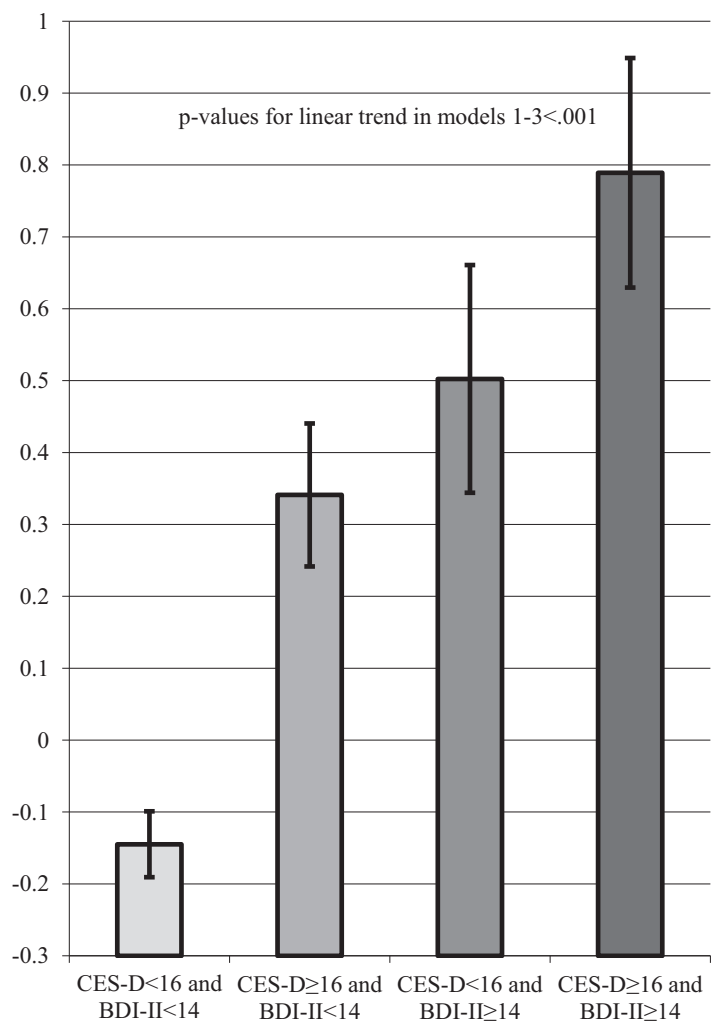

Although the effects of maternal depressive symptoms during pregnancy were clearly independent of symptoms reported after pregnancy, maternal depressive symptoms after pregnancy still played a role in two important ways: symptoms after pregnancy both partially mediated and added to the prenatal effects. These findings emphasize that both the pre- and the postnatal periods should be targets of preventive interventions, and reinforce the assessment of maternal depressive symptoms in routine antenatal and postpartum health care. ${ }^{2}$

The effects of maternal depressive symptoms during pregnancy on child psychiatric problems were also independent of maternal physician-diagnosed depression before pregnancy, although the effects were more pronounced and evident on all types of child psychiatric problems in the group who did not report physician-diagnosed depression before pregnancy. Among those with history of depression, intrauterine effects did not systematically add to the effects 
on internalizing symptoms but did predict externalizing and total problems. These somewhat contrasting findings may well reflect the much larger group of mothers with no physician-diagnosed depression before pregnancy available for analysis in our study.

Fetal overexposure to maternal glucocorticoids and inflammatory cytokines may underlie the prenatal programming effects. For instance, previous studies have demonstrated that higher maternal depressive symptoms during pregnancy are associated with higher mRNA levels of the glucocorticoid receptor (GR) and mineralocorticoid receptor genes in the placenta, ${ }_{4}^{4}$ and that higher placental GR mediate the effects of maternal depressive symptoms on infant regulatory behavior. ${ }^{5}$ Other studies have pointed to associations of maternal depression during pregnancy with epigenetic modifications of the GR gene in the placenta and fetal cord blood DNA, ${ }^{3}$ and have found crosssectional associations between altered GR gene methylation in DNA from peripheral blood leukocytes with adolescent internalizing problems. ${ }^{37}$ Also, higher maternal prenatal pro-inflammatory marker levels have been associated with both maternal depressive symptoms during pregnancy ${ }^{6,7}$ and offspring autism risk. ${ }^{38}$ However, the sociobiological pathways underlying the development of maternal depression and child psychopathology are beyond the scope of this study. Further studies unraveling these underlying mechanisms and studies focusing on the underlying genetic and epigenetic mechanisms are warranted.

Strengths of our study include a sizable homogenous sample, prospective design, repeated measurements of depressive symptoms during pregnancy and concurrently when rating child's psychiatric problems, and data on multiple important covariates. The homogeneity of the sample, however, is also a limitation, as is the follow-up sample attrition that was not independent of maternal characteristics. Half of the original cohort was lost to follow-up, which limits the external validity of our findings. Furthermore, we had a single informant on child problems. Using multiple informants would have given a more comprehensive picture of the associations. However, maternal depressive symptoms during pregnancy have previously been shown to predict child psychiatric problems, whether these were assessed by parents, teachers, self-reports, or clinical interviews. $^{8-19}$ Another limitation is that we had data on paternal depressive symptoms for only a subsample. Furthermore, although we had data on paternal depressive symptoms when the child was 6 months old, we did not have paternal depressive symptoms available when the mother was pregnant. Although adjustment for paternal depressive symptoms at 6 months did not influence our findings, further studies are needed to clarify the contribution of paternal depressive symptoms to maternal intrauterine effects. Paternal depression is an important covariate implicating familial confounding; however, adjustment for paternal depressive symptoms did not influence our findings. Despite the fact that we made adjustments for family structure, we lacked data on relationship stress that may contribute to the association between maternal depression and child psychopathology. ${ }^{8}$ Moreover, generalizations from our findings cannot be made to psychiatric disorders, as we measured psychiatric problems dimensionally. Because the mothers rated their depressive symptoms after pregnancy concurrently to child problems, shared method variance may have inflated the effect size estimates of the associations found, as mothers with depression may perceive more problems in their children. Also the mediation effects observed do not, strictly defined, evidence mediation, because child wellbeing may also influence maternal mental state. However, reverse causation cannot explain the prenatal effects.

In conclusion, our prospective study showed that higher maternal depressive symptoms during pregnancy predict significantly higher psychiatric problems in children. These associations were nonspecific to pregnancy trimester and gestational week and independent of, although partially mediated by, maternal depressive symptoms after pregnancy. Psychiatric problem levels were greatest in children whose mothers reported clinically significant depressive symptoms across pregnancy trimesters and both during and after pregnancy. Ongoing studies will unravel the biological and psychosocial mechanisms and will enable the design of preventive, targeted, family-based interventions, which, according to our findings, should focus both on the mother and her infant and start from early pregnancy onward. $\varepsilon$

\section{CG Clinical Guidance}

- Our findings show that maternal depressive symptoms should be assessed as a part of routine antenatal and postpartum care because of their adverse consequences for both the mothers and their children.

- Maternal depressive symptoms during pregnancy predict increased psychiatric problems in children independently of cardio-metabolic pregnancy disorders and maternal depressive symptoms postpartum.

- Maternal depressive symptoms show high stability throughout pregnancy and remain stable from pregnancy to postpartum, and have additive effects on child psychiatric problems.

- Early interventions may prevent psychiatric problems in both the mother and the child.

Accepted October 18, 2016

Drs. M. Lahti, Tuovinen, Pesonen, J. Lahti, Heinonen, and Räikkönen and Ms. Savolainen are with the Institute of Behavioural Sciences, University of Helsinki, Finland. Drs. M. Lahti and Reynolds are with the Queen's Medical Research Institute, University of Edinburgh, UK. Dr. J. Lahti is with the Helsinki Collegium for Advanced Studies, University of Helsinki, Finland. Drs. Hämäläinen, Laivuori, Villa, and Kajantie are with the Helsinki University Hospital and University of Helsinki, Finland. Dr. Laivuori is with the Institute for Molecular Medicine Finland, University of Helsinki, Finland and Dr. Kajantie is with the National Institute for Health and Welfare, Helsinki, Finland and Oulu University Hospital and University of Oulu, Finland. 
This study was funded by the Academy of Finland, Signe and Ane Gylleberg Foundation, Finnish Graduate School of Psychology, Emil Aaltonen Foundation, EVO (special state subsidy for health science research), Finnish Medical Foundation, Jane and Aatos Erkko Foundation, Novo Nordisk Foundation, Päivikki and Sakari Sohlberg Foundation, Sigrid Juselius Foundation, EraNet Neuron, Sir Jules Thorn Charitable Trust, and University of Helsinki.

A preliminary study abstract was presented at the $45^{\text {th }}$ International Society of Psychoneuroendocrinology-Conference in Edinburgh, UK, 2015 and published in Psychoneuroendocrinology. 2015;61:12

The authors thank Jari Lipsanen, MA, University of Helsinki, Finland for his statistical assistance.

\section{REFERENCES}

1. Bennett HA, Einarson A, Taddio A, Koren G, Einarson TR. Prevalence of depression during pregnancy: systematic review. Obstet Gynecol. 2004; 103:698-709.

2. Marcus SM, Flynn HA, Blow FC, Barry KL. Depressive symptoms among pregnant women screened in obstetrics settings. J Womens Health (Larchmt). 2003;12:373-380.

3. Palma-Gudiel H, Córdova-Palomera A, Eixarch E, Deuschle M, Fañanás L. Maternal psychosocial stress during pregnancy alters the epigenetic signature of the glucocorticoid receptor gene promoter in their offspring: a meta-analysis. Epigenetics. 2015;10:893-902.

4. Reynolds RM, Pesonen AK, O'Reilly J, et al. Depressive symptoms throughout pregnancy are associated with increased placental glucocorticoid sensitivity. Psychol Med. 2015;45:2023-2030.

5. Räikkönen K, Pesonen AK, O'Reilly JR, et al. Maternal depressive symptoms during pregnancy, placental expression of genes regulating glucocorticoid and serotonin function and infant regulatory behaviors. Psychol Med. 2015;45:3217-3226.

6. Christian LM, Franco A, Glaser R, Iams JD. Depressive symptoms are associated with elevated serum proinflammatory cytokines among pregnant women. Brain Behav Immun. 2009;23:750-754.

7. Shelton MM, Schminkey DL, Groer MW. Relationships among prenatal depression, plasma cortisol, and inflammatory cytokines. Biol Res Nurs. 2015;17:295-302

8. Betts KS, Williams GM, Najman JM, Alati R. Maternal depressive, anxious, and stress symptoms during pregnancy predict internalizing problems in adolescence. Depress Anxiety. 2014;31:9-18.

9. Davis EP, Sandman CA. Prenatal psychobiological predictors of anxiety risk in preadolescent children. Psychoneuroendocrinology. 2012; 37:1224-1233.

10. de Bruijn AT, van Bakel HJ, van Baar AL. Sex differences in the relation between prenatal maternal emotional complaints and child outcome. Early Hum Dev. 2009;85:319-324

11. Korhonen M, Luoma I, Salmelin R, Tamminen T. A longitudinal study of maternal prenatal, postnatal and concurrent depressive symptoms and adolescent well-being. J Affect Disord. 2012;136:680-692.

12. Leis JA, Heron J, Stuart EA, Mendelson T. Associations between maternal mental health and child emotional and behavioral problems: does prenatal mental health matter? J Abnorm Child Psychol. 2014;42:161-171.

13. O'Donnell KJ, Glover V, Barker ED, O'Connor TG. The persisting effect of maternal mood in pregnancy on childhood psychopathology. Dev Psychopathol. 2014;26:393-403.

14. Pawlby S, Hay DF, Sharp D, Waters CS, O'Keane V. Antenatal depression predicts depression in adolescent offspring: prospective longitudinal community-based study. J Affect Disord. 2009;113:236-243.

15. Pearson RM, Evans J, Kounali D, et al. Maternal depression during pregnancy and the postnatal period: risks and possible mechanisms for offspring depression at age 18 years. JAMA Psychiatry. 2013;70: 1312-1319.

16. Sandman CA, Buss $C$, Head $K$, Davis EP. Fetal exposure to maternal depressive symptoms is associated with cortical thickness in late childhood. Biol Psychiatry. 2015;77:324-334.

17. Van Batenburg-Eddes T, Brion MJ, Henrichs J, et al. Parental depressive and anxiety symptoms during pregnancy and attention problems in children: a cross-cohort consistency study. J Child Psychol Psychiatry. 2013;54:591-600.

18. Velders FP, Dieleman G, Henrichs J, et al. Prenatal and postnatal psychological symptoms of parents and family functioning: the impact on child emotional and behavioural problems. Eur Child Adolesc Psychiatry. 2011;20:341-345.
Disclosure: Drs. M. Lahti, Tuovinen, Pesonen, J. Lahti, Heinonen, Hämäläinen, Laivuori, Villa, Reynolds, Kajantie, Räikkönen, and Ms. Savolainen report no biomedical financial interests or potential conflicts of interest.

Correspondence to Marius Lahti, PhD, Institute of Behavioural Sciences, Siltavuorenpenger 1A, 00014 University of Helsinki, Finland; e-mail: marius. lahti@helsinki.fi

0890-8567/ \$36.00/@2016 American Academy of Child and Adolescent Psychiatry

hitp://dx.doi.org/10.1016/i.jaac.2016.10.007
19. Winsper C, Wolke D, Lereya T. Prospective associations between prenatal adversities and borderline personality disorder at 11-12 years. Psychol Med. 2015;45:1025-1037.

20. Hu R, Li Y, Zhang Z, Yan W. Antenatal depressive symptoms and the risk of preeclampsia or operative deliveries: a meta-analysis. PLoS One. 2015;10:e0119018.

21. Molyneaux E, Poston L, Ashurst-Williams S, Howard LM. Obesity and mental disorders during pregnancy and postpartum: a systematic review and meta-analysis. Obstet Gynecol. 2014;123:857-867.

22. Tuovinen S, Aalto-Viljakainen T, Eriksson JG, et al. Maternal hypertensive disorders during pregnancy: adaptive functioning and psychiatric and psychological problems of the older offspring. Br J Obstet Gynaecol. 2014; 121:1482-1491.

23. van Lieshout RJ, Robinson M, Boyle MH. Maternal pre-pregnancy body mass index and internalizing and externalizing problems in offspring. Can J Psychiatry. 2013;58:151-159.

24. Xiang AH, Wang $X$, Martinez MP, et al. Association of maternal diabetes with autism in offspring. JAMA. 2015;313:1425-1434.

25. Villa PM, Kajantie E, Räikkönen $\mathrm{K}$, et al. Aspirin in the prevention of preeclampsia in high-risk women: a randomised placebo-controlled PREDO Trial and a meta-analysis of randomised trials. Br J Obstet Gynaecol. 2013;120:64-74

26. Radloff LS. The CES-D Scale: A self-report depression scale for research in the general population. Appl Psychol Measure. 1977;1:385-401.

27. Vilagut G, Forero CG, Barbaglia G, Alonso J. Screening for depression in the general population with the Center for Epidemiologic Studies Depression (CES-D): a systematic review with meta-analysis. PLoS One. 2016;11:e0155431.

28. Beck AT, Steer RA, Brown GK. Manual for the Beck Depression Inventory-II. San Antonio, TX: Psychological Corporation; 1996.

29. Erford BT, Johnson E, Bardoshi G. Meta-analysis of the English version of the Beck Depression Inventory-Second Edition. Meas Eval Couns Dev. 2016;49:3-33.

30. Maloni JA, Park S, Anthony MK, Musil CM. Measurement of antepartum depressive symptoms during high-risk pregnancy. Res Nurs Health. 2005;28:16-26.

31. Nast I, Bolten M, Meinlschmidt G, Hellhammer DH. How to measure prenatal stress? A systematic review of psychometric instruments to assess psychosocial stress during pregnancy. Paediatr Perinat Epidemiol. 2013;27:313-322.

32. Achenbach TM, Rescorla LA. Manual for the ASEBA Preschool Form and Profiles. Burlington, VT: University of Vermont, Research Center for Children, Youth, and Families; 2000

33. Rescorla LA. Assessment of young children using the Achenbach System of Empirically Based Assessment (ASEBA). Ment Retard Dev Disabil Res Rev. 2005;11:226-237.

34. American Diabetes Association. Diagnosis and classification of diabetes mellitus. Diabetes Care. 2014;37(Suppl 1):S81-S90.

35. Steegers EA, von Dadelszen P, Duvekot JJ, Pijnenborg R. Pre-eclampsia. Lancet. 2010;376:631-644.

36. Duthie L, Reynolds RM. Changes in the maternal hypothalamicpituitary-adrenal axis in pregnancy and postpartum: influences on maternal and fetal outcomes. Neuroendocrinology. 2013;98:106-115.

37. van der Knaap LJ, van Oort FV, Verhulst FC, Oldehinkel AJ, Riese H. Methylation of NR3C1 and SLC6A4 and internalizing problems. The TRAILS study. J Affective Disord. 2015;180:97-103.

38. Brown AS, Sourander A, Hinkka-Yli-Salomäki S, McKeague IW Sundvall J, Surcel HM. Elevated maternal C-reactive protein and autism in a national birth cohort. Mol Psychiatry. 2014;19:259-264. 
FIGURE S1 Latent profile analysis on the course of maternal depressive symptoms during pregnancy. Note: The figure shows the mean levels of depressive symptoms at different gestational weeks in three latent profile analysis-derived groups of mothers who showed consistently low, moderate, and high levels of depressive symptoms throughout pregnancy. CES-D = Center for Epidemiologic Studies Depression Scale.

CES-D sumscore

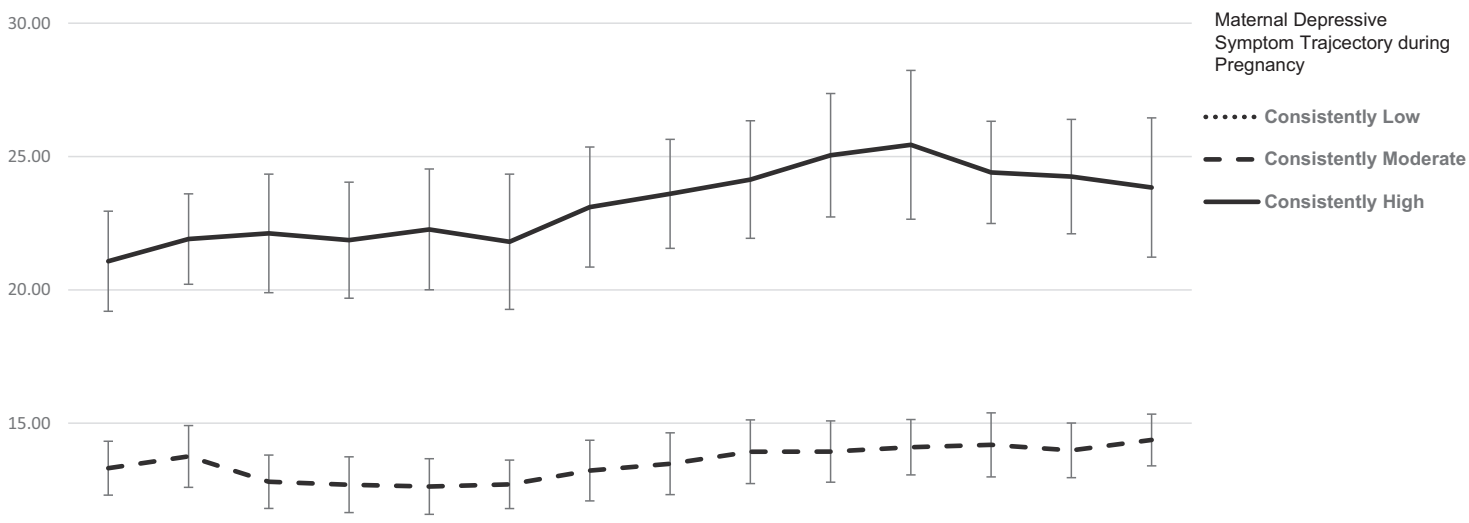

10.00

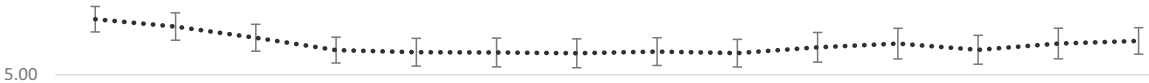

0.00

$24 \quad 26$

Gestational week

$\begin{array}{llllll}28 & 30 & 32 & 34 & 36 & 38\end{array}$


FIGURE S2 Maternal depressive symptoms during pregnancy and child psychiatric problems in groups with and without pregnancy disorders. Note: Maternal depressive symptoms during pregnancy and child psychiatric problems among those with maternal pregnancy disorders (pre-pregnancy obesity, gestational hypertensive disorders, and gestational diabetes) (panel A: $\mathrm{n}=541$ ) and among those without (panel $\mathrm{B}: \mathrm{n}=1,755$ ) are shown. Unstandardized regression coefficients (B) and their $95 \% \mathrm{Cls}$ of linear regression models adjusted for the covariates in models 1 to 3 . The third models refer here to regression models adjusted further for maternal depressive symptoms at the time of rating the child's problems.

\section{A With pregnancy Disorders}

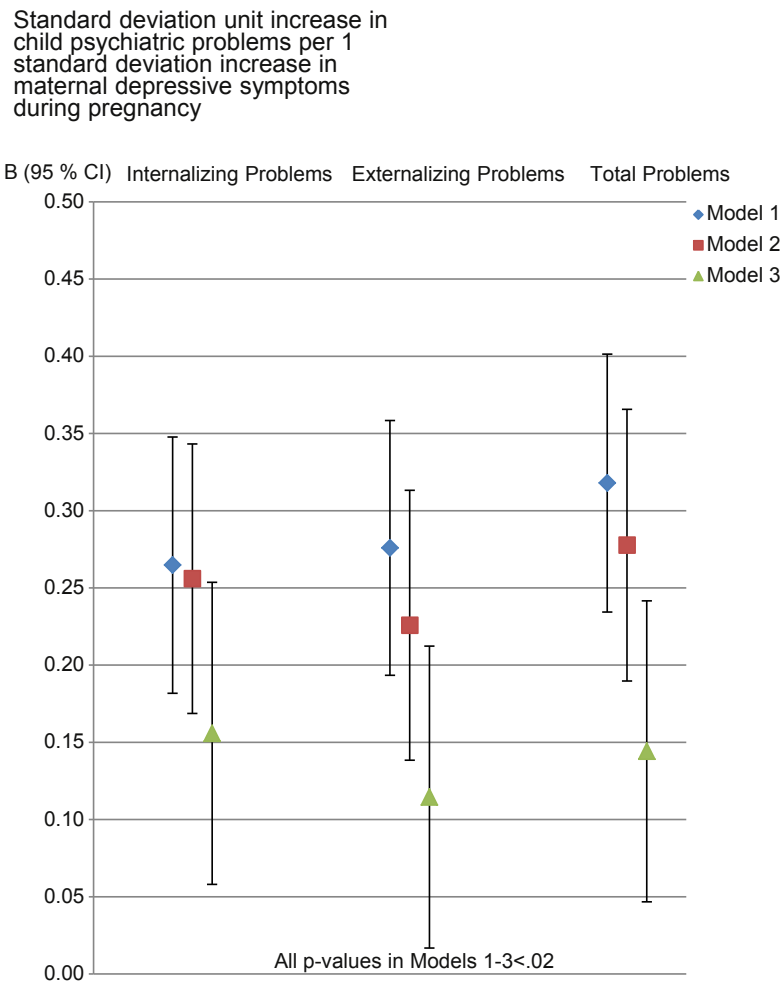

\section{B Without pregnancy Disorders}

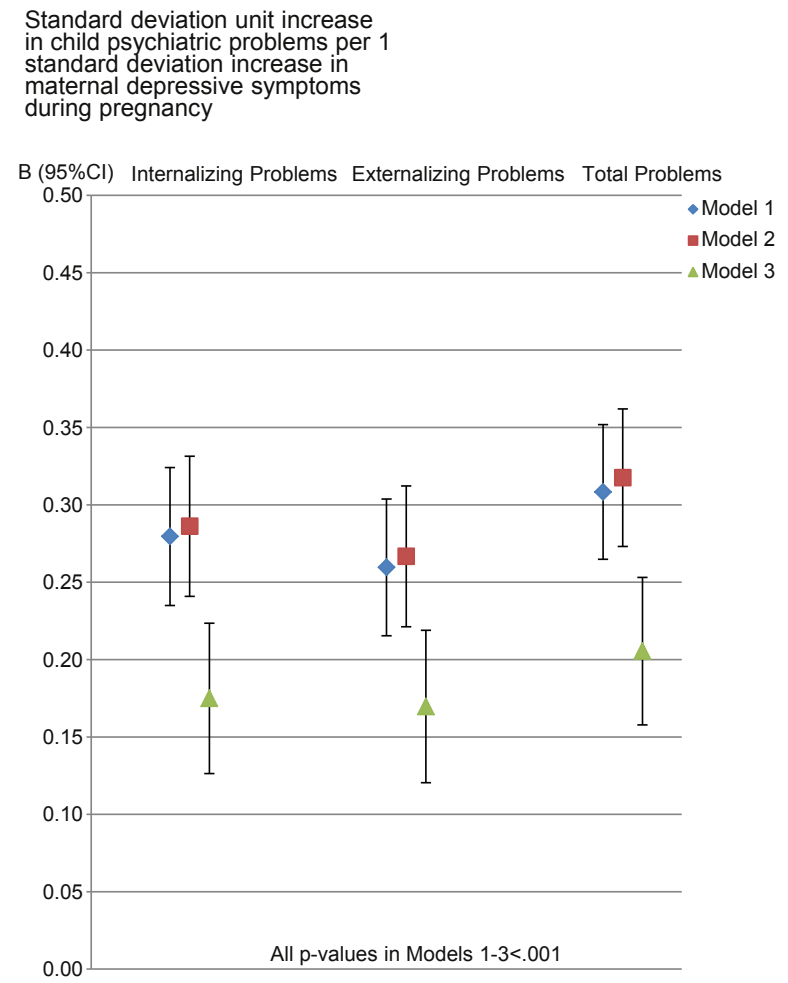


FIGURE S3 Maternal depressive symptoms during pregnancy and child psychiatric problems in groups with and without maternal diagnosis of depression before pregnancy. Note: Maternal depressive symptoms during pregnancy and child psychiatric problems among those with maternal self-reported history of physician-diagnosed depression before pregnancy (panel $A: n=214$ ) and among those without (panel $B: n=1,982$ ) are shown. Unstandardized regression coefficients (B) and their $95 \%$ Cls of linear regression models adjusted for the covariates in models 1 to 4 .

\section{A With History of Depression}

Standard deviation unit increase in child psychiatric problems per 1 standard deviation unit increase in maternal depressive symptoms during pregnancy

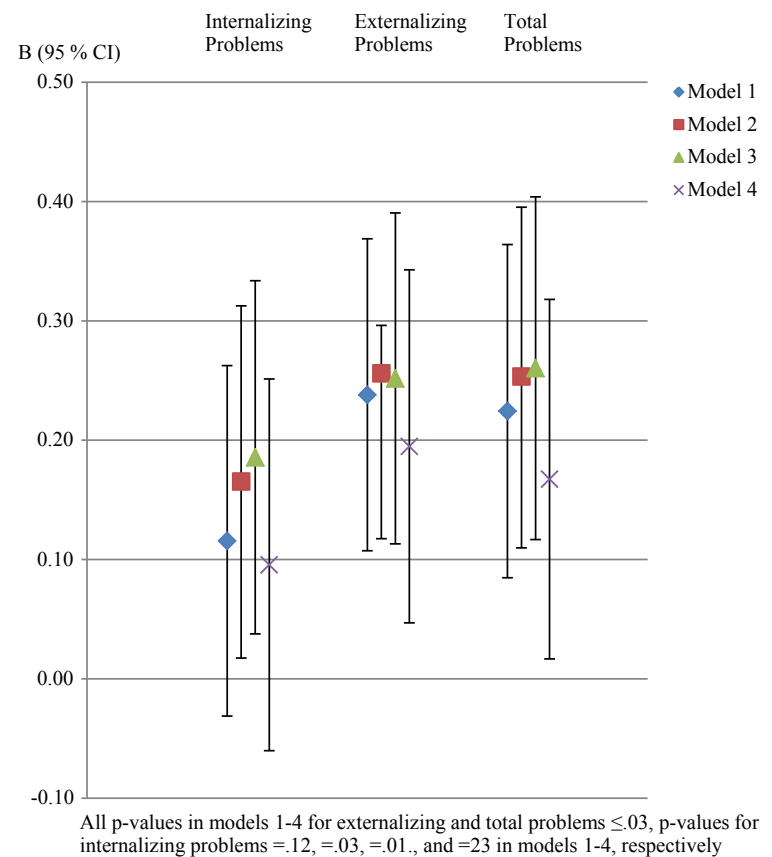

\section{B Without History of Depression}

Standard deviation unit increase in child psychiatric problems per 1 standard deviation unit increase in maternal depressive symptoms during pregnancy

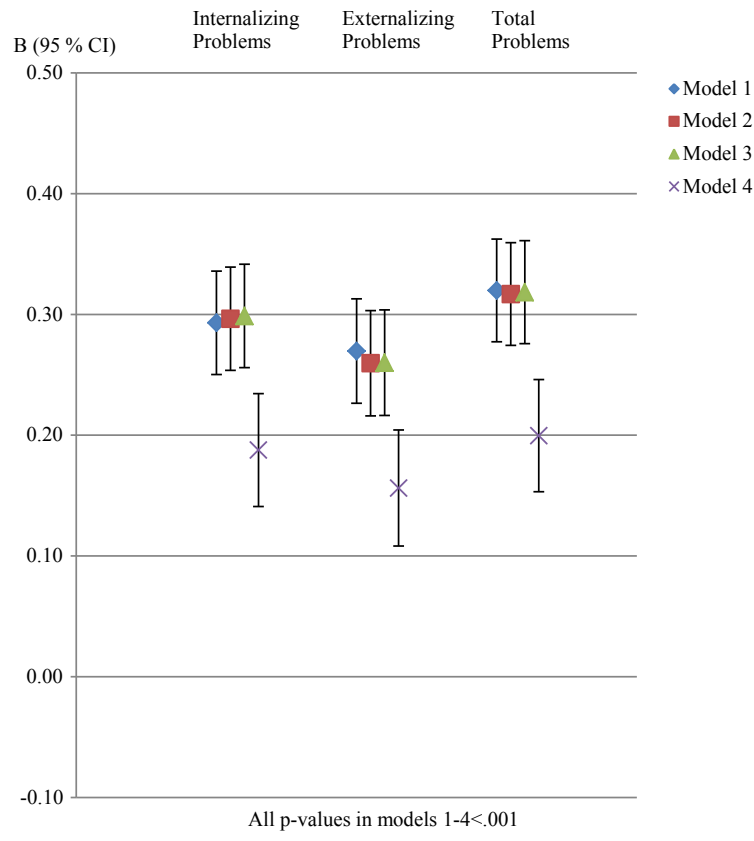


TABLE S1 Associations of Covariates With Child Psychiatric Problems

\begin{tabular}{|c|c|c|c|c|c|c|}
\hline \multirow[b]{3}{*}{ Characteristics } & \multicolumn{6}{|c|}{ CBCL Scale } \\
\hline & \multicolumn{2}{|c|}{ Internalizing Problems ${ }^{a}$} & \multicolumn{2}{|c|}{ Externalizing Problems ${ }^{a}$} & \multicolumn{2}{|c|}{ Total Problems $^{\mathrm{a}}$} \\
\hline & $r /$ Mean Difference $b$ & $p$ & $r /$ Mean Difference ${ }^{b}$ & $p$ & $r /$ Mean Difference ${ }^{b}$ & $p$ \\
\hline \multicolumn{7}{|l|}{ Maternal characteristics } \\
\hline Age at delivery & -0.09 & $<.001$ & -0.11 & $<.001$ & -0.12 & $<.001$ \\
\hline Education: primary or secondary vs. tertiary & 0.05 & .31 & 0.11 & .01 & 0.08 & .05 \\
\hline Parity: primiparous vs. other & 0.40 & $<.001$ & 0.21 & $<.001$ & 0.34 & $<.001$ \\
\hline Family structure: single vs. cohabiting & 0.17 & .30 & 0.04 & .83 & 0.08 & .63 \\
\hline History of depression before pregnancy (yes/no) & 0.24 & .002 & 0.20 & .01 & 0.26 & $<.001$ \\
\hline Antidepressant use during pregnancy (yes/no) & 0.02 & .88 & 0.26 & .07 & 0.21 & .14 \\
\hline $\begin{array}{l}\text { Other psychotropic medication use during } \\
\text { pregnancy (yes } / \text { no) }\end{array}$ & 0.37 & .17 & 0.43 & .11 & 0.44 & .10 \\
\hline Alcohol use during pregnancy (yes/no) & 0.01 & .91 & 0.06 & .29 & 0.01 & .83 \\
\hline $\begin{array}{l}\text { Quit smoking during first trimester vs. no smoking } \\
\text { during pregnancy }\end{array}$ & 0.18 & .13 & 0.23 & .04 & 0.22 & .06 \\
\hline $\begin{array}{l}\text { Smoked throughout pregnancy vs. no smoking } \\
\text { during pregnancy }\end{array}$ & 0.31 & .01 & 0.49 & $<.001$ & 0.44 & .001 \\
\hline $\begin{array}{l}\text { Smoked throughout pregnancy vs. quit during first } \\
\text { trimester }\end{array}$ & 0.13 & .43 & 0.25 & .13 & 0.21 & .20 \\
\hline Pre-pregnancy obesity (yes/no) & -0.03 & .63 & 0.09 & .18 & 0.04 & .56 \\
\hline $\begin{array}{l}\text { Gestational hypertension-spectrum disorder } \\
\text { (yes/no) }\end{array}$ & -0.00 & .95 & -0.00 & .96 & -0.00 & .99 \\
\hline Chronic hypertension (yes/no) & -0.00 & $>.99$ & -0.08 & .50 & -0.04 & .74 \\
\hline Gestational diabetes (yes/no) & -0.02 & .80 & -0.02 & .76 & -0.01 & .87 \\
\hline Type 1 diabetes (yes/no) & 0.17 & .56 & 0.39 & .20 & 0.27 & .37 \\
\hline \multicolumn{7}{|l|}{ Child characteristics } \\
\hline Sex (male vs. female) & -0.03 & .48 & 0.26 & $<.001$ & 0.15 & $<.001$ \\
\hline Gestational age & -0.03 & .13 & -0.03 & .21 & -0.03 & .16 \\
\hline Birthweight adjusted for gestational age and sex & -0.08 & $<.001$ & -0.05 & .03 & -0.06 & .005 \\
\hline Age at follow-up & 0.07 & .002 & -0.08 & $<.001$ & -0.04 & .03 \\
\hline Paternal depressive symptoms in child's infancy & 0.14 & $<.001$ & 0.08 & .003 & 0.13 & $<.001$ \\
\hline \multicolumn{7}{|c|}{$\begin{array}{l}\text { Note: } C B C L=\text { Child Behavior Checklist. } \\
{ }^{a} \text { Child psychiatric problem scores are expressed in standard deviation units. } \\
b_{\mathrm{r}} \text { refers to Pearson correlation coefficients of continuous covariates with child psychiatric problems; mean difference refers to mean group differences between the } \\
\quad \text { groups of the categorical covariates in child psychiatric problems in independent-samples } t \text { test analyses. }\end{array}$} \\
\hline
\end{tabular}


TABLE S2 Associations Between Trimester-Weighted Mean of Maternal Depressive Symptoms During Pregnancy and Child Psychiatric Problems

\begin{tabular}{|c|c|c|c|c|c|c|c|c|}
\hline & Model $1(n=2,296)^{a}$ & & Model $2(n=2,296)^{a}$ & & Model $3(n=2,296)^{a}$ & & Model $4(n=2,269)^{a, b}$ & \\
\hline CBCL Scale & B $(95 \% \mathrm{Cl})^{\mathrm{c}}$ & $p$ & B $(95 \% \mathrm{Cl})^{\mathrm{c}}$ & $p$ & B $(95 \% \text { Cl) })^{\mathrm{c}}$ & $p$ & B $(95 \% \mathrm{Cl})^{\mathrm{c}}$ & $p$ \\
\hline \multicolumn{9}{|l|}{ Main Scales } \\
\hline Internalizing Problems & $0.28(0.24-0.32)$ & $<.001$ & $0.28(0.24-0.32)$ & $<.001$ & $0.29(0.25-0.33)$ & $<.001$ & $0.18(0.13-0.22)$ & $<.001$ \\
\hline Externalizing Problems & $0.26(0.23-0.30)$ & $<.001$ & $0.26(0.22-0.30)$ & $<.001$ & $0.26(0.22-0.30)$ & $<.001$ & $0.16(0.12-0.20)$ & $<.001$ \\
\hline Total Problems & $0.31(0.27-0.35)$ & $<.001$ & $0.31(0.27-0.35)$ & $<.001$ & $0.31(0.27-0.35)$ & $<.001$ & $0.20(0.15-0.24)$ & $<.001$ \\
\hline \multicolumn{9}{|l|}{ Syndrome Scales } \\
\hline Emotionally Reactive & $0.41(0.33-0.49)$ & $<.001$ & $0.41(0.33-0.48)$ & $<.001$ & $0.42(0.34-0.49)$ & $<.001$ & $0.25(0.17-0.34)$ & $<.001$ \\
\hline Anxious/Depressed & $0.56(0.44-0.68)$ & $<.001$ & $0.56(0.44-0.68)$ & $<.001$ & $0.56(0.44-0.68)$ & $<.001$ & $0.35(0.23-0.48)$ & $<.001$ \\
\hline Somatic Complaints & $0.37(0.29-0.45)$ & $<.001$ & $0.38(0.30-0.47)$ & $<.001$ & $0.39(0.30-0.47)$ & $<.001$ & $0.26(0.17-0.35)$ & $<.001$ \\
\hline Withdrawn & $0.29(0.23-0.36)$ & $<.001$ & $0.33(0.26-0.39)$ & $<.001$ & $0.33(0.26-0.39)$ & $<.001$ & $0.20(0.13-0.27)$ & $<.001$ \\
\hline Sleep Problems & $0.30(0.24-0.36)$ & $<.001$ & $0.30(0.24-0.36)$ & $<.001$ & $0.30(0.24-0.36)$ & $<.001$ & $0.20(0.13-0.27)$ & $<.001$ \\
\hline Attention Problems & $0.35(0.28-0.43)$ & $<.001$ & $0.35(0.28-0.43)$ & $<.001$ & $0.35(0.27-0.43)$ & $<.001$ & $0.22(0.13-0.30)$ & $<.001$ \\
\hline Aggressive Behavior & $0.46(0.38-0.54)$ & $<.001$ & $0.45(0.37-0.53)$ & $<.001$ & $0.45(0.37-0.53)$ & $<.001$ & $0.28(0.19-0.37)$ & $<.001$ \\
\hline \multicolumn{9}{|l|}{ DSM-Oriented Scales } \\
\hline Affective Problems & $0.30(0.25-0.35)$ & $<.001$ & $0.30(0.25-0.36)$ & $<.001$ & $0.31(0.25-0.36)$ & $<.001$ & $0.20(0.14-0.25)$ & $<.001$ \\
\hline Anxiety Problems & $0.45(0.36-0.55)$ & $<.001$ & $0.44(0.34-0.54)$ & $<.001$ & $0.44(0.34-0.54)$ & $<.001$ & $0.29(0.19-0.40)$ & $<.001$ \\
\hline $\begin{array}{l}\text { Pervasive Developmental } \\
\text { Problems }\end{array}$ & $0.32(0.26-0.39)$ & $<.001$ & $0.34(0.27-0.41)$ & $<.001$ & $0.34(0.28-0.41)$ & $<.001$ & $0.21(0.14-0.29)$ & $<.001$ \\
\hline ADHD Problems & $0.39(0.31-0.47)$ & $<.001$ & $0.40(0.32-0.48)$ & $<.001$ & $0.40(0.32-0.48)$ & $<.001$ & $0.25(0.16-0.33)$ & $<.001$ \\
\hline $\begin{array}{l}\text { Oppositional Defiant } \\
\text { Problems }\end{array}$ & $0.31(0.25-0.37)$ & $<.001$ & $0.31(0.24-0.37)$ & $<.001$ & $0.31(0.25-0.37)$ & $<.001$ & $0.18(0.12-0.25)$ & $<.001$ \\
\hline \\
\hline \multicolumn{9}{|c|}{$\begin{array}{l}\text { Note: } A D H D=\text { attention-deficit/hyperactivity disorder; } C B C L=\text { Child Behavior Checklist. } \\
\text { aModel I is adjusted for the age and sex of the child; model } 2 \text { further for family structure, maternal age at delivery, parity, education level, type I diabetes, chronic hypertension, history of depression before pregnancy, } \\
\text { antidepressant and other psychotropic medication use, alcohol use and smoking during pregnancy, gestation length, and child's birthweight adjusted for gestation length and sex; model } 3 \text { further for pre-pregnancy } \\
\text { obesity, hypertension-spectrum pregnancy disorders, and gestational diabetes; and model } 4 \text { for maternal depressive symptoms after pregnancy at the time of rating the child's psychiatric problems. } \\
{ }^{b} \text { The fourth analytic model includes } 2,269 \text { participants, as } 27 \text { mothers had missing data on depressive symptoms after pregnancy and were excluded from these analyses. In contrast, participants with missing values on } \\
\text { categorical covariates were dummy coded into separate categories in the regression analysis. }\end{array}$} \\
\hline
\end{tabular}


TABLE S3 Maternal Biweekly Depressive Symptoms During Pregnancy and Child Psychiatric Problems

\begin{tabular}{|c|c|c|c|}
\hline & Internalizing Problems & Externalizing Problems & Total Problems \\
\hline Maternal Depressive Symptoms at & B $(95 \%$ Cl) & B $(95 \%$ Cl) & B $(95 \%$ Cl) \\
\hline \multicolumn{4}{|c|}{$12-13$ weeks of gestation $(n=2,193)$} \\
\hline Model 1 & $0.22(0.17-0.26)$ & $0.22(0.18-0.27)$ & $0.25(0.21-0.29)$ \\
\hline Model 2 & $0.22(0.18-0.26)$ & $0.22(0.18-0.26)$ & $0.25(0.21-0.29)$ \\
\hline Model 3 & $0.22(0.18-0.26)$ & $0.22(0.18-0.26)$ & $0.25(0.21-0.29)$ \\
\hline Model 4 & $0.12(0.07-0.16)$ & $0.13(0.08-0.17)$ & $0.14(0.10-0.18)$ \\
\hline \multicolumn{4}{|l|}{$14-15$ weeks of gestation $(n=2,142)$} \\
\hline Model 1 & $0.22(0.18-0.26)$ & $0.22(0.17-0.26)$ & $0.25(0.21-0.29)$ \\
\hline Model 2 & $0.22(0.18-0.26)$ & $0.21(0.16-0.25)$ & $0.25(0.21-0.29)$ \\
\hline Model 3 & $0.22(0.18-0.26)$ & $0.20(0.16-0.25)$ & $0.25(0.21-0.29)$ \\
\hline Model 4 & $0.12(0.08-0.17)$ & $0.12(0.07-0.16)$ & $0.14(0.10-0.18)$ \\
\hline \multicolumn{4}{|c|}{$16-17$ weeks of gestation $(n=2,110)$} \\
\hline Model 1 & $0.23(0.19-0.27)$ & $0.21(0.17-0.25)$ & $0.26(0.21-0.30)$ \\
\hline Model 2 & $0.23(0.19-0.28)$ & $0.21(0.17-0.25)$ & $0.25(0.21-0.29)$ \\
\hline Model 3 & $0.24(0.20-0.28)$ & $0.21(0.16-0.25)$ & $0.25(0.21-0.29)$ \\
\hline Model 4 & $0.14(0.10-0.18)$ & $0.12(0.08-0.16)$ & $0.15(0.11-0.19)$ \\
\hline \multicolumn{4}{|c|}{$18-19$ weeks of gestation $(n=2,133)$} \\
\hline Model 1 & $0.21(0.17-0.25)$ & $0.20(0.16-0.24)$ & $0.24(0.20-0.28)$ \\
\hline Model 2 & $0.20(0.16-0.24)$ & $0.19(0.15-0.23)$ & $0.23(0.19-0.27)$ \\
\hline Model 3 & $0.20(0.16-0.25)$ & $0.19(0.15-0.23)$ & $0.23(0.19-0.27)$ \\
\hline Model 4 & $0.12(0.07-0.16)$ & $0.11(0.07-0.15)$ & $0.13(0.09-0.17)$ \\
\hline \multicolumn{4}{|c|}{$20-21$ weeks of gestation $(n=2,111)$} \\
\hline Model 1 & $0.23(0.19-0.27)$ & $0.22(0.17-0.26)$ & $0.25(0.21-0.30)$ \\
\hline Model 2 & $0.23(0.19-0.27)$ & $0.21(0.16-0.25)$ & $0.25(0.21-0.29)$ \\
\hline Model 3 & $0.23(0.19-0.27)$ & $0.20(0.16-0.25)$ & $0.25(0.21-0.29)$ \\
\hline Model 4 & $0.13(0.09-0.18)$ & $0.12(0.07-0.16)$ & $0.15(0.11-0.19)$ \\
\hline \multicolumn{4}{|c|}{$22-23$ weeks of gestation $(n=2,081)$} \\
\hline Model 1 & $0.22(0.17-0.26)$ & $0.22(0.18-0.26)$ & $0.25(0.20-0.29)$ \\
\hline Model 2 & $0.21(0.17-0.25)$ & $0.21(0.17-0.25)$ & $0.24(0.20-0.28)$ \\
\hline Model 3 & $0.21(0.17-0.26)$ & $0.21(0.16-0.25)$ & $0.24(0.20-0.28)$ \\
\hline Model 4 & $0.12(0.07-0.16)$ & $0.12(0.08-0.16)$ & $0.14(0.09-0.18)$ \\
\hline \multicolumn{4}{|c|}{$24-25$ weeks of gestation $(n=2,055)$} \\
\hline Model 1 & $0.23(0.19-0.27)$ & $0.21(0.17-0.25)$ & $0.25(0.20-0.29)$ \\
\hline Model 2 & $0.22(0.18-0.26)$ & $0.20(0.15-0.24)$ & $0.23(0.19-0.27)$ \\
\hline Model 3 & $0.22(0.18-0.27)$ & $0.19(0.15-0.24)$ & $0.23(0.19-0.28)$ \\
\hline Model 4 & $0.13(0.09-0.18)$ & $0.11(0.07-0.16)$ & $0.14(0.09-0.18)$ \\
\hline \multicolumn{4}{|c|}{$26-27$ weeks of gestation $(n=2,076)$} \\
\hline Model 1 & $0.23(0.18-0.27)$ & $0.22(0.18-0.26)$ & $0.25(0.21-0.29)$ \\
\hline Model 2 & $0.22(0.18-0.26)$ & $0.21(0.17-0.25)$ & $0.24(0.20-0.28)$ \\
\hline Model 3 & $0.22(0.18-0.26)$ & $0.21(0.17-0.25)$ & $0.24(0.20-0.28)$ \\
\hline Model 4 & $0.12(0.08-0.17)$ & $0.12(0.08-0.17)$ & $0.14(0.10-0.18)$ \\
\hline \multicolumn{4}{|c|}{$28-29$ weeks of gestation $(n=2,055)$} \\
\hline Model 1 & $0.26(0.22-0.30)$ & $0.22(0.18-0.26)$ & $0.27(0.23-0.31)$ \\
\hline Model 2 & $0.26(0.21-0.30)$ & $0.21(0.17-0.25)$ & $0.26(0.22-0.31)$ \\
\hline Model 3 & $0.26(0.22-0.30)$ & $0.21(0.17-0.25)$ & $0.26(0.22-0.31)$ \\
\hline Model 4 & $0.16(0.12-0.21)$ & $0.12(0.08-0.16)$ & $0.16(0.12-0.20)$ \\
\hline \multicolumn{4}{|c|}{$30-31$ weeks of gestation $(n=2,056)$} \\
\hline Model 1 & $0.25(0.20-0.29)$ & $0.22(0.18-0.26)$ & $0.27(0.23-0.31)$ \\
\hline Model 2 & $0.25(0.21-0.29)$ & $0.22(0.18-0.26)$ & $0.27(0.23-0.31)$ \\
\hline Model 3 & $0.25(0.21-0.30)$ & $0.22(0.18-0.26)$ & $0.27(0.23-0.31)$ \\
\hline Model 4 & $0.16(0.11-0.20)$ & $0.13(0.08-0.17)$ & $0.16(0.12-0.21)$ \\
\hline
\end{tabular}


TABLE S3 Continued

\begin{tabular}{|c|c|c|c|}
\hline & Internalizing Problems & Externalizing Problems & Total Problems \\
\hline Maternal Depressive Symptoms at & B $(95 \% \mathrm{Cl})$ & B $(95 \%$ Cl) & B $(95 \%$ Cl) \\
\hline \multicolumn{4}{|c|}{$32-33$ weeks of gestation $(n=2,061)$} \\
\hline Model 1 & $0.26(0.22-0.30)$ & $0.23(0.19-0.27)$ & $0.28(0.24-0.32)$ \\
\hline Model 2 & $0.27(0.23-0.31)$ & $0.23(0.19-0.27)$ & $0.28(0.24-0.32)$ \\
\hline Model 3 & $0.27(0.23-0.31)$ & $0.23(0.19-0.27)$ & $0.28(0.24-0.32)$ \\
\hline Model 4 & $0.18(0.13-0.22)$ & $0.14(0.09-0.18)$ & $0.18(0.13-0.22)$ \\
\hline \multicolumn{4}{|c|}{$34-35$ weeks of gestation $(n=2,020)$} \\
\hline Model 1 & $0.25(0.20-0.29)$ & $0.22(0.18-0.26)$ & $0.27(0.22-0.31)$ \\
\hline Model 2 & $0.25(0.21-0.29)$ & $0.21(0.17-0.25)$ & $0.26(0.22-0.30)$ \\
\hline Model 3 & $0.25(0.21-0.30)$ & $0.21(0.17-0.25)$ & $0.26(0.22-0.31)$ \\
\hline Model 4 & $0.16(0.12-0.21)$ & $0.12(0.08-0.17)$ & $0.16(0.12-0.21)$ \\
\hline \multicolumn{4}{|c|}{$36-37$ weeks of gestation $(n=1,957)$} \\
\hline Model 1 & $0.23(0.19-0.27)$ & $0.20(0.16-0.24)$ & $0.25(0.21-0.29)$ \\
\hline Model 2 & $0.24(0.19-0.28)$ & $0.20(0.16-0.24)$ & $0.25(0.21-0.30)$ \\
\hline Model 3 & $0.24(0.20-0.28)$ & $0.20(0.16-0.24)$ & $0.26(0.21-0.30)$ \\
\hline Model 4 & $0.16(0.11-0.20)$ & $0.12(0.08-0.17)$ & $0.17(0.12-0.21)$ \\
\hline \multicolumn{4}{|c|}{$38-39$ weeks of gestation $(n=1,669)$} \\
\hline Model 1 & $0.22(0.18-0.27)$ & $0.19(0.14-0.23)$ & $0.24(0.19-0.28)$ \\
\hline Model 2 & $0.23(0.19-0.28)$ & $0.18(0.14-0.23)$ & $0.24(0.19-0.28)$ \\
\hline Model 3 & $0.23(0.19-0.28)$ & $0.19(0.14-0.23)$ & $0.24(0.20-0.29)$ \\
\hline Model 4 & $0.15(0.10-0.20)$ & $0.11(0.06-0.16)$ & $0.15(0.10-0.20)$ \\
\hline \multicolumn{4}{|c|}{$\begin{array}{l}\text { Note: Model } 1 \text { is adjusted for child's age and sex; model } 2 \text { further for family structure, maternal age at delivery, parity, education, type } 1 \text { diabetes, chronic hypertension, } \\
\text { history of depression before pregnancy, antidepressant and other psychotropic medication use, alcohol use and smoking during pregnancy, gestation length and } \\
\text { child's birthweight adjusted for gestation length and sex; model } 3 \text { further for pre-pregnancy obesity, hypertension-spectrum pregnancy disorders, and gestational } \\
\text { diabetes; and model } 4 \text { also for maternal depressive symptoms after pregnancy at the time of rating child's psychiatric problems. B values are unstandardized regression } \\
\text { coefficients, and } 95 \% \mathrm{Cl} \text { are their } 95 \% \text { confidence intervals, from linear regression models. All independent and dependent variables are expressed in standard } \\
\text { deviation units. All associations are highly statistically significant } / \mathrm{p}<.001 \text {. }\end{array}$} \\
\hline
\end{tabular}

TABLE S4 Age-Specific Associations Between Trimester-Weighted Mean of Maternal Depressive Symptoms During Pregnancy and Child Psychiatric Problems

\begin{tabular}{|c|c|c|c|c|c|c|c|c|}
\hline \multirow[b]{2}{*}{ Child Age } & \multicolumn{2}{|l|}{ Model 1} & \multicolumn{2}{|l|}{ Model 2} & \multicolumn{2}{|l|}{ Model 3} & \multicolumn{2}{|l|}{ Model 4} \\
\hline & B $(95 \% \mathrm{Cl})$ & $p$ & B $(95 \% \mathrm{Cl})$ & $p$ & B $(95 \% \mathrm{Cl})$ & $p$ & B $(95 \% \mathrm{Cl})$ & $p$ \\
\hline \multicolumn{9}{|l|}{$1.9-3.9$ y $(n=1,564)$} \\
\hline Internalizing Problems & $0.29(0.25-0.34)$ & $<.001$ & $0.30(0.25-0.34)$ & $<.001$ & $0.30(0.25-0.34)$ & $<.001$ & $0.19(0.14-0.24)$ & $<.001$ \\
\hline Externalizing Problems & $0.27(0.22-0.32)$ & $<.001$ & $0.27(0.22-0.31)$ & $<.001$ & $0.26(0.22-0.31)$ & $<.001$ & $0.17(0.12-0.22)$ & $<.001$ \\
\hline Total Problems & $0.32(0.28-0.37)$ & $<.001$ & $0.32(0.27-0.37)$ & $<.001$ & $0.32(0.27-0.37)$ & $<.001$ & $0.21(0.16-0.26)$ & $<.001$ \\
\hline \multicolumn{9}{|c|}{ - } \\
\hline Internalizing Problems & $0.25(0.18-0.32)$ & $<.001$ & $0.26(0.18-0.33)$ & $<.001$ & $0.26(0.19-0.34)$ & $<.001$ & $0.15(0.07-0.24)$ & $<.001$ \\
\hline Externalizing Problems & $0.25(0.18-0.32)$ & $<.001$ & $0.25(0.18-0.32)$ & $<.001$ & $0.25(0.18-0.32)$ & $<.001$ & $0.15(0.06-0.23)$ & $<.001$ \\
\hline Total Problems & $0.29(0.22-0.36)$ & $<.001$ & $0.29(0.22-0.36)$ & $<.001$ & $0.29(0.22-0.36)$ & $<.001$ & $0.17(0.09-0.25)$ & $<.001$ \\
\hline $\begin{array}{l}\text { Note: Model } 1 \text { is adjusted for } \\
\text { hypertension, history of dep } \\
\text { length, and child's birthwe } \\
\text { gestational diabetes; and } \\
\text { main scales are unstandarc } \\
\text { expressed in standard devi }\end{array}$ & $\begin{array}{l}\text { oression before pregnanc } \\
\text { ight adjusted for gestatic } \\
\text { nodel } 4 \text { for maternal dep } \\
\text { dized regression coeffici } \\
\text { ation units. }\end{array}$ & ents, and & $\begin{array}{l}\text { and sex; model } 3 \text { furthe } \\
\text { mptoms after pregnancy } \\
\text { their } 95 \% \mathrm{Cl} \text { are from lit }\end{array}$ & near regre. & $\begin{array}{l}\text { rnal age at delivery, parit } \\
\text { dication use, alcohol use } \\
\text { regnancy obesity, hyper } \\
\text { of rating the child's psy } \\
\text { ssion analyses. Both the }\end{array}$ & indepen & $\begin{array}{l}\text { on level, type } 1 \text { diabetes } \\
\text { king during pregnancy, } \\
\text { ectrum pregnancy disoro } \\
\text { oblems. B values and } 93 \\
\text { lent and dependent varic }\end{array}$ & $\begin{array}{l}\text {, chronic } \\
\text { gestation } \\
\text { ders, and } \\
5 \% \mathrm{Cl} \text { for } \\
\text { ables are }\end{array}$ \\
\hline
\end{tabular}

